\title{
Ovarian carcinomas with genetic and epigenetic BRCAI loss have distinct molecular abnormalities
}

Joshua Z Press $^{\dagger 1}$, Alessandro De Luca ${ }^{\dagger 2}$, Niki Boyd ${ }^{2}$, Sean Young2,3, Armelle Troussard ${ }^{2}$, Yolanda Ridge ${ }^{3}$, Pardeep Kaurah ${ }^{3}$, Steve E Kalloger ${ }^{4}$, Katherine A Blood ${ }^{2}$, Margaret Smith ${ }^{5}$, Paul T Spellmann ${ }^{6}$, Yuker Wang7, Dianne M Miller ${ }^{8}$, Doug Horsman²,5, Malek Faham7, C Blake Gilks*2,4, Joe Gray ${ }^{6}$ and David G Huntsman ${ }^{2,3,4}$

Address: ${ }^{1}$ Department of Obstetrics and Gynecology, University of British Columbia, Vancouver, British Columbia, Canada, ${ }^{2}$ Department of Pathology and Laboratory Medicine, University of British Columbia, Vancouver, British Columbia, Canada, ${ }^{3}$ Hereditary Cancer Program, British Columbia Cancer Agency, Vancouver, British Columbia, Canada, ${ }^{4}$ Genetic Pathology Evaluation Centre of the Prostate Centre, Vancouver General Hospital, Vancouver, British Columbia, Canada, ${ }^{5}$ Molecular Genetics, The Royal Melbourne Hospital, Parkville, Australia, ${ }^{6}$ Life Sciences Division, Lawrence Berkeley National Laboratory, University of California, San Francisco, California, USA, ${ }^{7}$ Affymetrix Inc. 7300 Shoreline Blvd South, San Francisco, California, USA and ${ }^{8}$ Department of Gynecologic Oncology, University of British Columbia, Vancouver, British Columbia, Canada

Email: Joshua Z Press - drjpress@telus.net; Alessandro De Luca - alessandro.deluca@vch.ca; Niki Boyd - nboyd@bccancer.bc.ca; Sean Young - syoung@bccancer.bc.ca; Armelle Troussard - atroussa@bccrc.ca; Yolanda Ridge - yridge@bccancer.bc.ca; Pardeep Kaurah - pkaurah@bccancer.bc.ca; Steve E Kalloger - skalloger@mac.com; Katherine A Blood - kblood@bccrc.ca; Margaret Smith - margie.smith@mh.org.au; Paul T Spellman - ptspellman@lbl.gov; Yuker Wang - Yuker_Wang@affymetrix.com; Dianne M Miller - Dianne.Miller@vch.ca; Doug Horsman - DHorsman@bccancer.bc.ca; Malek Faham - Malek_Faham@affymetrix.com; C Blake Gilks* - Blake.Gilks@vch.ca; Joe Gray - JWGray@lbl.gov; David G Huntsman - dhuntsma@bccancer.bc.ca

* Corresponding author †Equal contributors

Published: 22 January 2008

BMC Cancer 2008, 8:17 doi:10.1186/147|-2407-8-17
Received: 24 July 2007

Accepted: 22 January 2008

This article is available from: http://www.biomedcentral.com/I47/-2407/8/17

(c) 2008 Press et al; licensee BioMed Central Ltd.

This is an Open Access article distributed under the terms of the Creative Commons Attribution License (http://creativecommons.org/licenses/by/2.0), which permits unrestricted use, distribution, and reproduction in any medium, provided the original work is properly cited.

Background: Subclassification of ovarian carcinomas can be used to guide treatment and determine prognosis. Germline and somatic mutations, loss of heterozygosity (LOH), and epigenetic events such as promoter hypermethylation can lead to decreased expression of BRCAI/ 2 in ovarian cancers. The mechanism of BRCAI/2 loss is a potential method of subclassifying high grade serous carcinomas.

Methods: A consecutive series of 49 ovarian cancers was assessed for mutations status of BRCA I and BRCA2, LOH at the BRCAI and BRCA2 loci, methylation of the BRCAI promoter, BRCAI, BRCA2, PTEN, and PIK3CA transcript levels, PIK3CA gene copy number, and BRCAI, p2I, p53, and WT-I immunohistochemistry.

Results: Eighteen (37\%) of the ovarian carcinomas had germline or somatic BRCAI mutations, or epigenetic loss of BRCAI. All of these tumours were high-grade serous or undifferentiated type. None of the endometrioid $(n=5)$, clear cell $(n=4)$, or low grade serous $(n=2)$ carcinomas showed loss of BRCAI, whereas $47 \%$ of the 38 high-grade serous or undifferentiated carcinomas had loss of BRCAI. It was possible to distinguish high grade serous carcinomas with BRCAI mutations from those with epigenetic BRCAI loss: tumours with BRCAI mutations typically had decreased PTEN mRNA levels while those with epigenetic loss of BRCAI had copy number gain of PIK3CA. Overexpression of p53 with loss of p2I expression occurred significantly more 
frequently in high grade serous carcinomas with epigenetic loss of BRCAI, compared to high grade serous tumors without loss of BRCAI.

Conclusion: High grade serous carcinomas can be subclassified into three groups: BRCAI loss (genetic), BRCAI loss (epigenetic), and no BRCAI loss. Tumors in these groups show distinct molecular alterations involving the PI3K/AKT and p53 pathways.

\section{Background}

Ovarian cancer is the most fatal gynecological cancer in North American women and the fifth most common cause of cancer death. Epithelial ovarian carcinomas (EOC) are subclassified according to tumor cell type and grade. These different subtypes of ovarian cancer are associated with different molecular characteristics: high grade serous cancers typically contain TP53 mutations [1,2], low grade serous carcinomas often have RAS-RAF pathway activation and mutations in the KRAS and BRAF genes [3], low-grade endometrioid cancers are associated with mutations in the beta-catenin gene, CTNNB1 [4], and mucinous cancers frequently have mutations in KRAS [5]. Accurate subclassification of ovarian cancers is essential because different subtypes of ovarian cancer respond differently to treatment and have different prognoses [6].

The majority of ovarian cancers are of serous subtype [7]. In a study of 220 ovarian carcinomas, over half were categorized as serous and over $90 \%$ of these serous ovarian cancers were high grade (grade II or III) [8]. High grade serous ovarian cancers are associated with BRCA1 or BRCA2 mutations [9-11]. BRCA1, located at 17q21 [12$14]$, and BRCA2, located at 13q12-q13 [15,16] both encode tumor suppressors involved in repairing doublestranded DNA breaks and maintaining genomic stability [17-19] Germline BRCA1 or BRCA2 mutations are present in $10 \%$ to $15 \%$ of all EOCs $[20,21]$. Less commonly, EOCs contain somatic mutations in these genes [22]. In addition, aberrant expression of BRCA1 or BRCA2 may occur through loss of heterozygosity or, in the case of BRCA1, promoter hypermethylation [23-27]. Unlike breast cancer, where patients with germline mutations in BRCA1 or BRCA2 have cancers that are distinct from sporadic breast cancers on the basis of morphology or gene profiling [28-30], ovarian cancers with germline BRCA1 or BRCA2 mutations are indistinguishable from their sporadic counterparts $[11,23,31-33]$. High grade serous ovarian cancers that have functional BRCA1 or BRCA2 are currently not separable from high grade serous cancers that have loss of function of these proteins, based on routine histopathological examination. The challenge is to find methods to distinguish these subtypes of high grade serous cancers; this would stratify patients based on the underlying molecular events during oncogenesis, which is potentially highly relevant as these cancers may respond differently to treatment. This has recently been demon- strated in vitro: inhibitors of poly(ADP-ribose) polymerase (PARP1) were found to be able to target and kill cells deficient in either BRCA1 or BRCA2 [34,35]. PARP1 binds to single-stranded DNA breaks, attracting proteins to repair DNA. Inhibition of PARP1 allows these single stranded breaks to progress to double stranded breaks through the resulting collapse of replication forks $[34,36]$. The preferred double-strand break repair mechanism is homologous recombination which relies on the activity of BRCA1 and BRCA2. Thus, cells with loss of BRCA1 or BRCA2 function that are treated with PARP1 inhibitors are unable to repair DNA breaks, which leads to crisis and cell death.

We collected and analysed 49 consecutive ovarian tumor samples from consenting women diagnosed with invasive, non-mucinous EOC who were undergoing debulking surgery. We pathologically characterized these samples and analysed them for BRCA1 and BRCA2 mutations, loss of heterozygosity at both loci, mRNA levels of BRCA1 and BRCA2, expression of BRCA1, and BRCA1 promoter hypermethylation. In light of previous studies showing that promoter hypermethylation of BRCA2 is rarely if ever encountered in ovarian carcinoma [37-39], we did not undertake similar studies on the BRCA2 promoter. We then attempted to determine whether molecular profiles could be used to distinguish high grade serous cancers with BRCA1 mutations (germline or somatic), from high grade serous cancers with epigenetic loss of BRCA1 through promoter hypermethylation, and high grade serous cancers without BRCA1 loss. We focused on the PI3K/AKT and p53 pathways which play important roles in ovarian cancer [40-43].

\section{Methods}

\section{Recruitment and tumor samples}

Between January 2004 and September 2005 all women undergoing primary debulking surgery for ovarian carcinoma were invited to participate in this study at the Vancouver General Hospital and British Columbia Cancer Agency in Vancouver, Canada. Women with mucinous and borderline tumors, and women who had received pre-operative chemotherapy were excluded. Pathology was reviewed by a single pathologist (CBG). Serous tumors were classified as low or high-grade as described previously [44]; all undifferentiated and clear cell carcinomas were considered high-grade. Endometrioid carcino- 
mas were graded as grade 1,2 , or 3 according to the Silverberg grading system [45]. Ethical approval was obtained from the University of British Columbia Ethics Board (\#H02-61375 and \#H03-70606).

\section{DNA and RNA extraction}

Cancer tissue was split with part stored at -80 degrees and the facing tissue fixed in formalin and placed in paraffin blocks. H\&E sections were reviewed to ensure samples consisted of $\geq 70 \%$ tumor cells. DNA was extracted using the Puregene DNA Purification Kit (Gentra Systems, Inc, Wicklow, Ireland) according to manufacturer's instructions from whole blood (germline analysis) or tumor samples (somatic analysis). RNA was isolated with Trizol (Invitrogen, Carlsbad, CA) according to standard protocols.

\section{Loss of heterozygosity analysis}

Somatic loss of BRCA1/BRCA2 in tumor tissue was assessed for $\mathrm{LOH}$ using microsatellite markers for BRCA1 $\left(\mathrm{D} 17 \mathrm{~S} 855 \quad\left(60^{\circ} \mathrm{C}\right), \quad \mathrm{D} 17 \mathrm{~S} 1185 \quad\left(58^{\circ} \mathrm{C}\right), \quad \mathrm{D} 17 \mathrm{~S} 1323\right.$ $\left(56^{\circ} \mathrm{C}\right)$, and $\left.\mathrm{D} 17 \mathrm{~S} 1325\left(56^{\circ} \mathrm{C}\right)\right)[46]$, and BRCA2 $\left(\mathrm{D} 13 \mathrm{~S} 260\left(60^{\circ} \mathrm{C}\right), \mathrm{D} 13 \mathrm{~S} 171\left(50^{\circ} \mathrm{C}\right), \mathrm{D} 13 \mathrm{~S} 267\left(53^{\circ} \mathrm{C}\right)\right.$, D13S217 $\left(55^{\circ} \mathrm{C}\right)$ ) [9]. PCR products were electrophoresed in an ABI Prism 3100 Genetic Analyzer (Applied Biosystems, Foster City, CA), and analyzed with Genescan v3.1 software (Applied Biosystems, Foster City, CA). LOH was defined as a complete or partial $(\leq 50 \%)$ signal reduction of one allele in at least one marker. Microsatellite instability (MSI) was defined as the presence of novel alleles in the tumor DNA that were not present in normal DNA in at least one marker [47].

\section{dHPLC mutation screening and mutation analysis}

Screening for BRCA1/BRCA2 mutations was performed using denaturing high performance liquid chromatography (dHPLC). Tumor DNA was mixed in a 3:1 ratio with corresponding germline DNA for all tumors shown to possess $\mathrm{LOH}$ to ensure that $\mathrm{LOH}$ did not mask somatic mutations [48]. For example, with intratumoral LOH, and mutation of the remaining allele, dHPLC screening would give a false negative result. If the mutation is a germline mutation it will be picked up on dHPLC screening of germline DNA, however, a somatic mutation would be missed in both tumor and germline DNA without DNA mixing. PCR primers and conditions were developed by the Royal Melbourne Hospital (Australia) and are available on request. PCR primers were used to amplify each exon of BRCA1 (24 exons) and BRCA2 (26 exons). All exons with abnormal dHPLC profiles were PCR amplified and bi-directionally sequenced to identify mutations using ABI BigDye terminator v3.1 cycle sequencing kit (Applied Biosytems, Foster City, CA) and an ABI Prism 3100 Genetic Analyzer (Applied Biosystems, Foster City, CA).

\section{Multiplex Ligation-dependent Probe Amplification (MLPA) screening}

For the identification of germline BRCA1 single and multiple exon deletions or duplications, multiplex ligationdependent probe amplification analysis (MLPA) kits SALSA P002 BRCA1 and SALSA P087 BRCA1 (MRC Holland, Amsterdam, NL) were used according to manufacturer directions. A reduction or increase in RPA values to $<0.7$ or $>1.3$ was considered an indication of a deletion or a duplication, respectively [49].

\section{BRCAI and FANCF promoter hypermethylation analysis}

The BRCA1 methylation status of each tumor was assessed using a technique similar to the MethyLight assay described previously [50]. Briefly, $500 \mathrm{ng}$ of sample DNA was subjected to sodium bisulfite modification using the EZ DNA Methylation-Gold Kit, as recommended by the manufacturer (Zymo Research, Orange, CA). After bisulfite treatment, DNA was amplified using real-time PCR with oligonucleotide primers complementary to a region of the MYOD1 promoter that did not contain any CpG dinucleotides but did contain non-CpG cytosines to ascertain the amount of converted input templates in each sample. Hypermethylation of the BRCA1 promoter was then examined by real-time PCR amplification of bisulfite-modified DNA using oligonucleotide primers specific for a fully methylated bisulfite-converted portion of BRCA1 promoter such that only CpG islands that were methylated at every CpG dinucleotide interrogated by the primers and probes would be amplified and generate fluorescent signal. The sequences of the primers used to amplify and detect methylated BRCA1 promoter region were 5'-TAGAGTTTCGAGAGACGTTTGGTTT-3' (forward primer) and 5'-CGCTTTTCCGTTACCACGA-3' (reverse primer). The primers for MYOD1 were 5'-CCA ACTCCA AATCCCCTC TCTAT-3' (forward primer) and 5'-TGATTAATTAGATTGGGTTTAGAGAAGGA-3' (reverse primer). The amount of methylated DNA (PMR, percentage of methylated reference) [51] at the BRCA1 locus was calculated by dividing the BRCA1: MYOD1 ratio of a sample by the BRCA1: MYOD1 ratio of CpG methylated Jurkat genomic DNA (New England Biolabs, Ipswich, MA) and multiplying by 100 . Reactions using CpG methylated Jurkat genomic DNA were used to normalize for any difference in amplification efficiencies between BRCA1 and MYOD1. The PMR serves as an index of the percentage of bisulfite converted input copies of DNA that are fully methylated at the primer hybridization sites. The PMR values obtained by MethyLight were dichotomized at 4 PMR for statistical purposes as described previously [51]. Samples containing 4 PMR or higher were designated as methylated, whereas samples containing less than 4 PMR were designated as unmethylated. It is important to note, however, that the PMR may be $>1$ if copies of MYOD 1 are deleted relative to the gene of interest, or copies of the 
gene of interest are gained relative to MYOD1 in any given sample. PCR experiments were carried out in a volume of $10 \mu \mathrm{L}$ with 384-well plates and an Applied Biosystems 7900 HT Sequence Detector (Applied Biosystems, Foster City, CA). The fluorescence signal of the quantitative methylation-specific PCR was generated by SYBR Green I. Samples (10 ng bisulfite-treated DNA) were run in triplicate containing $5 \mu \mathrm{L}$ SYBR Green Master Mix (Applied Biosystems, Foster City, CA) and 5 pmol of each forward and reverse primer. Bisulfite-converted $\mathrm{CpG}$ methylated Jurkat Genomic DNA (New England Biolabs, Ipswich, $\mathrm{MA}$ ) served as a positive control and was used to generate a standard curve to quantify the amount of fully methylated promoters in each reaction. PCR amplification was done by means of the following procedure: $95^{\circ} \mathrm{C}$ for 15 minutes, followed by 40 cycles at $95^{\circ} \mathrm{C}$ for 15 seconds, $62^{\circ} \mathrm{C}$ for 1 minute. A subsequent dissociation curve analysis checked the specificity of products. FANCF promoter hypermethylation was assessed using a HpaII digest assay and methylation-specific PCR protocol previously reported by Taniguchi et al [52].

\section{Real-time Q-RT-PCR}

Extracted RNA was treated with DNAse I (Invitrogen, Carlsbad, CA) prior to creating cDNA using random hexamer priming and MMLV reverse transcriptase (Invitrogen, Carlsbad, CA). Applied Biosystems Taqman primer/ probe kits (Hs00173233_m1 (BRCA1), Hs00609060_m1 (BRCA2), Hs01920652_s1 (PTEN), Hs00907966_m1(PIK3CA)) were used to quantify mRNA expression levels using real-time qRT-PCR [37] and an ABI Prism 7900 HT Sequence Detection System (Applied Biosystems, Foster City, CA). Relative gene expression quantification was calculated according to the comparative $\mathrm{Ct}$ method using human 18S ribosomal RNA (Applied Biosystems, Foster City, CA) and commercial RNA controls (Stratagene, La Jolla, CA). Relative quantification was

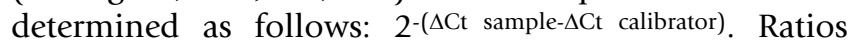
(tumor relative gene expression:average of all tumors) less than 0.7 or greater that 1.3 for were scored as decreased or increased mRNA expression, respectively.

\section{Immunohistochemistry}

The BRCA1 antibody Ab-1 (Oncogene, 1:50 dilution) was used and antigen retrieval was performed in $1 \times$ EDTA buffer ( $\mathrm{pH} 8.0$ ) by microwaving for 2 minutes, and then boiling in a waterbath for 30 minutes. Endogenous peroxide activity was blocked with $3 \%$ hydrogen peroxide and then sections were incubated with $2.5 \%$ normal horse blocking serum. Following incubation with the primary antibody, the Vector Laboratories (Burlingame, CA) ImmPRESS kit was used according to the manufacturer's recommendations to visualize antibody complexes. Nuclear staining was assessed by CBG, who was blinded to all other BRCA analysis. Tumors were considered
BRCA1 positive if greater than $1 \%$ of tumor nuclei showed staining. IHC was also performed with the following panel of previously validated antibodies using a Ventana (Tucson, AZ) automated immunostainer: p21 (Neomarkers, Fremont, CA, clone DCS-60.2, 1:100 dilution), p53 (Dako, Carpinteria, CA, clone DO-7, 1:400 dilution), and WT-1 (Dako, Carpinteria, CA, clone 6F-H2, 1:50 dilution). BRCA1 IHC was done on whole sections, while other IHC markers were assessed using sections from a tissue microarray constructed with two $0.6 \mathrm{~mm}$ cores per case.

\section{Molecular Inversion Probe (MIP) Copy Number}

The MIP copy number assay was done as described previously [53] with some modifications. Specifically, the current protocol is a modification of the Targeted Genotyping protocol commercialized by Affymetrix [54]. Test DNA samples were diluted to16 ng/ $\mu \mathrm{l}$. Molecular inversion probes were annealed to DNA by mixing $4.7 \mu \mathrm{l}$ of DNA (75 ng total), $0.75 \mu$ l of Buffer A, $1.1 \mu$ l of the 53 $\mathrm{K}$ molecular inversion probe pool (200 amol/ $\mu \mathrm{l} /$ probe) and $0.045 \mu \mathrm{l}$ of Enzyme A in a 384-well plate on ice. The reaction was incubated for $4 \mathrm{~min}$ at $20^{\circ} \mathrm{C}, 5 \mathrm{~min}$ at $95^{\circ} \mathrm{C}$, then overnight at $58^{\circ} \mathrm{C}$. Following annealing, $13 \mu \mathrm{l}$ of Buffer A and $1.25 \mu \mathrm{l}$ of Gap Fill Enzyme mix were added to each reaction and $9 \mu \mathrm{l}$ of reaction volume was transferred to each of two wells in a 96-well plate. Molecular inversion probes were circularized with $4 \mu \mathrm{l}$ of dNTP mix at $58^{\circ} \mathrm{C}$ for $10 \mathrm{~min}$. Linear probes and genomic DNA were eliminated by addition of $4 \mu \mathrm{l}$ of Exo Mix and incubation at $37^{\circ} \mathrm{C}$ for $15 \mathrm{~min}$, followed by universal primer amplification for $18 \mathrm{cycles}\left(20 \mathrm{sec}\right.$ at $95^{\circ} \mathrm{C}, 40 \mathrm{sec}$ at $64^{\circ} \mathrm{C}$, and $10 \mathrm{sec}$ at $72^{\circ} \mathrm{C}$ ). For labelling reactions, the product was further amplified for 10 cycles using labelled primers, then subjected to cleavage by HY Digest Mix at $37^{\circ} \mathrm{C}$ for 2 hours. The cleaved MIP products were mixed with Hybridization Cocktail, denatured, and hybridized to $70 \mathrm{~K}$ Universal Taq arrays at $39^{\circ} \mathrm{C}$ for $16 \mathrm{~h}$ (two arrays per sample). The overnight hybridized arrays were washed on a GeneChip ${ }^{\circledR}$ Fluidics Station FS450 and stained by SAPE at 5 ng/ $\mathrm{ml}$ (Invitrogen).

Copy number estimation was obtained from the hybridization signals as previously described [55], with the following modifications: the color-separation step was omitted as the single color readout on two arrays prevented the spectral overlap that occurs with multi-color readouts, and Langmuir correction was performed instead of linear calibration of allele signals [56]. Copy numbers over 3.0 were considered amplification events and copy numbers below 1.5 were considered deletion events.

\section{Data analysis}

Epigenetic BRCA1 loss was defined as having promoter hypermethylation accompanied by either low relative 
BRCA1 mRNA expression, negative BRCA1 IHC, or both low BRCA1 mRNA and negative BRCA1 IHC. Tumors without promoter hypermethylation and with positive BRCA1 IHC were not considered to have BRCA1 loss. Tumors with negative BRCA1 IHC without promoter hypermethylation were considered equivocal for BRCA1 loss. A chi-squared test or Fisher exact test was used to analyze categorical variables (MIP copy number, IHC) and a student's t-test was used to analyze continuous variables (RNA expression).

\section{Results}

Representative results of analysis for BRCA1 mutations, BRCA1 loss of heterozygosity, and BRCA1 promoter hypermethylation are shown in Figure 1.

BRCA1 findings for all tumors are presented as Figure 2. Based on these results, ovarian cancers were divided into six groups: (1) BRCA1 mutations, (2) BRCA1 epigenetic loss, (3) equivocal for BRCA1 loss, (4) high grade serous/ undifferentiated cancers without BRCA1 loss, (5) BRCA2 mutations, and (6) clear cell, endometrioid, and low grade serous cancers.

Nine of the samples (18\%) carried BRCA1 mutations (eight germline, one somatic) and three samples (6\%) had BRCA2 mutations (two germline, one somatic). No intragenic deletions in BRCA1 were detected by MLPA analysis. Nine samples (18\%) were found to have loss of BRCA1 due to epigenetic events; these samples all had hypermethylation of the BRCA1 promoter accompanied by decreased BRCA1 mRNA levels (relative qRT-PCR expression $<0.7$ ) and/or lack (less than $1 \%$ of tumour nuclei) of BRCA1 immunohistochemical staining. Five samples $(10 \%)$, which did not carry BRCA1 mutations, were all unmethylated at the BRCA1 promoter; these were classified as "equivocal for BRCA1 loss" because they fulfilled two of the following criteria: loss of heterozygosity (LOH) at the BRCA1 locus, decreased BRCA1 mRNA levels, or lack of BRCA1 immunohistochemical staining. All samples $(n=26)$ with BRCA1 or BRCA2 mutations, epigenetic loss of BRCA1, or classified as equivocal for BRCA1 loss were of high grade serous/undifferentiated type. Twelve tumors (24\%) of high grade serous/undifferentiated type did not have BRCA1 mutations or epigenetic loss, or BRCA2 mutations. Thus, considering only the 38 high grade serous/undifferentiated tumours in our study, $18(18 / 38,47 \%)$ had loss of BRCA1 either through genetic or epigenetic events, three $(3 / 38,8 \%)$ carried germline or somatic BRCA2 mutations, 12 (12/38, 32\%) had preservation of BRCA1 expression and no mutations in BRCA1 or BRCA2, and the remaining five tumors (5/ $38,13 \%$ ) were equivocal for BRCA1 loss and did not have BRCA2 mutations. FANCF promoter hypermethylation was not observed in any of these cases.
The remaining 11 tumour samples (22\%) (i.e. those cases other that the high grade serous/undifferentiated carcinomas) were either clear cell (4), endometrioid (5), or low grade serous type (2). These samples were all negative for BRCA1 or BRCA2 mutations, negative for BRCA1 promoter hypermethylation, and positive for BRCA1 expression as determined by immunohistochemistry.

We further analyzed the 35 high grade serous/undifferentiated tumour samples that did not contain BRCA2 mutations using a combination of MIP copy number, qRTPCR, and immunohistochemistry in order to determine whether these different groups could be classified according to specific molecular features other than BRCA1 or BRCA2 abnormalities (Figure 3). The number of tumors with BRCA2 mutations $(\mathrm{n}=3)$ was considered too small for meaningful further analysis of this subset and was therefore excluded. Thirty-one of these tumours were positive for WT1 expression by immunohistochemistry, a marker of serous cell type in EOC, thus confirming our histopathological subclassification [57]; all clear cell and endometrioid cancers in this study were negative for WT1 expression (data not shown). Currently, the group of high grade serous/undifferentiated carcinoma is indivisible based on morphology or routinely used diagnostic molecular markers. We specifically focused on the PI3K/AKT and p53 pathways which are known to be important in EOC. We found that those tumours with BRCA1 loss through genetic events differed according to several parameters from tumours with loss of BRCA1 due to epigenetic events. Most striking were differences in PIK3CA copy number as determined by the MIP copy number assay. While none of the BRCA1 mutation positive cases demonstrated an increased PIK3CA copy number almost all $(7 / 8)$ of the samples with epigenetic loss of BRCA1 had increased copy number at the PIK3CA locus. The PIK3CA copy number increases were low level (mean amplification ratio 2.7, range 1.7-4.9), and in all but one case amplification of PIK3CA was associated with amplification of the entire chromosomal arm. PIK3CA mRNA levels were assessed using qRT-PCR and relative mRNA levels were found to correlate with copy number ratios ( $\mathrm{p}=$ 0.02). Specificity of MIP copy number data was verified by assessing c-myc amplification; while PIK3CA copy number appeared to be selectively increased in specific subgroups, amplification at the c-myc locus was observed at similar frequencies in all subgroups. Interestingly, decreased PTEN mRNA levels observed in cancers with BRCA1 mutations and increased PI3KCA copy number in cancers with epigenetic loss of BRCA1 were almost mutually exclusive (Figure 4). These events represent two separate mechanisms of activation of the canonical PI3K/AKT pathway. 
(A)

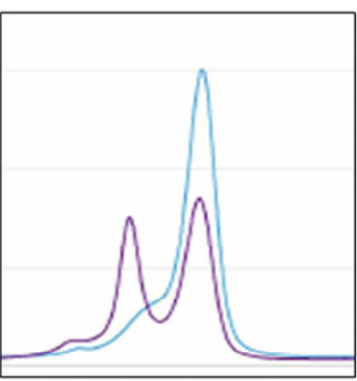

(B)

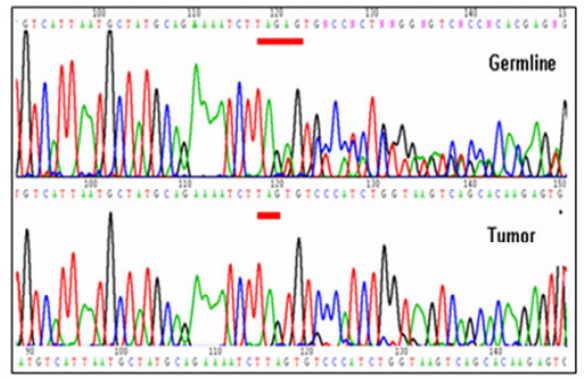

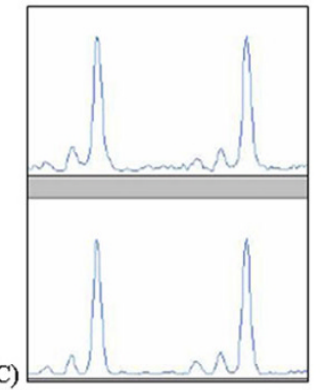

(D)

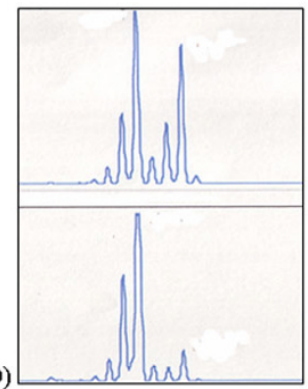

(E)
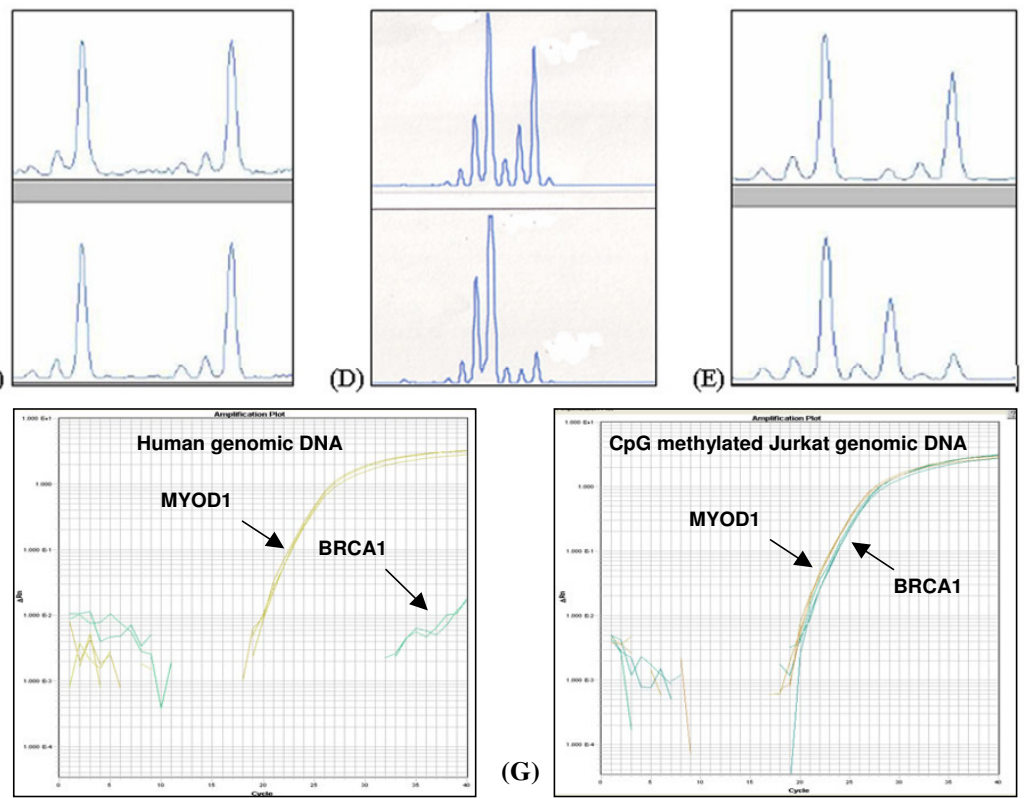

(F)
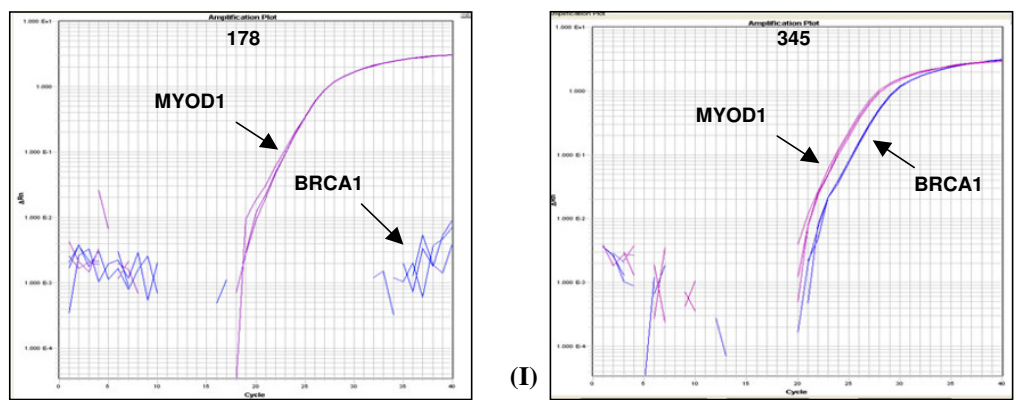

\section{Figure I}

Assessment of BRCAI loss (A) Mutation screening showing the abnormal denaturing high performance liquid chromatography profile corresponding to the I35I delAT mutation in tumor 223. The single blue line represents the electropherogram from a normal control, while the purple line represents the abnormal profile formed by the mutated exon IIc in tumor 223. (B) Direct DNA sequencing demonstrating the I85delAG mutation in tumor 283. Only the mutant allele is seen in the tumor because $\mathrm{LOH}$ is present. (C-E) Loss of heterozygosity (LOH) analysis using BRCA I-associated microsatellite markers visualized on an ABI Prism 3100 Genetic Analyzer, where LOH is defined as $>50 \%$ decrease in area under the curve when germline DNA (upper tracing) and tumor DNA (lower tracing) are compared. (C) The lack of LOH in tumor 240 demonstrated using microsatellite marker D I7SI I85, (D) LOH in tumor 283 demonstrated using microsatellite marker DI7S855. (E) Microsatellite instability demonstrated in tumor I56 using microsatellite marker DI7SI 185. (F, G, H, and I) Methylation analysis of BRCAI gene using fluorescence-based, quantitative, real-time PCR (TaqMan) using SYBR Green I as detection method. Two sets of primers, designed specifically for bisulfite converted DNA, were used: a methylated set for the BRCAI gene and a reference set (MYODI) to control for input DNA. Specificity of the reactions for methylated DNA were confirmed separately using human genomic DNA (unmethyated; F) and CpG methylated Jurkat genomic DNA (methylated; G), respectively. $\mathrm{H}$ and I show representative examples of results from assessment of BRCAI loss through promoter hypermethyation. Tumor 178 shows only unmethylated BRCAI promoter, while tumor 345 shows evidence of BRCAI promoter hypermethylation. 


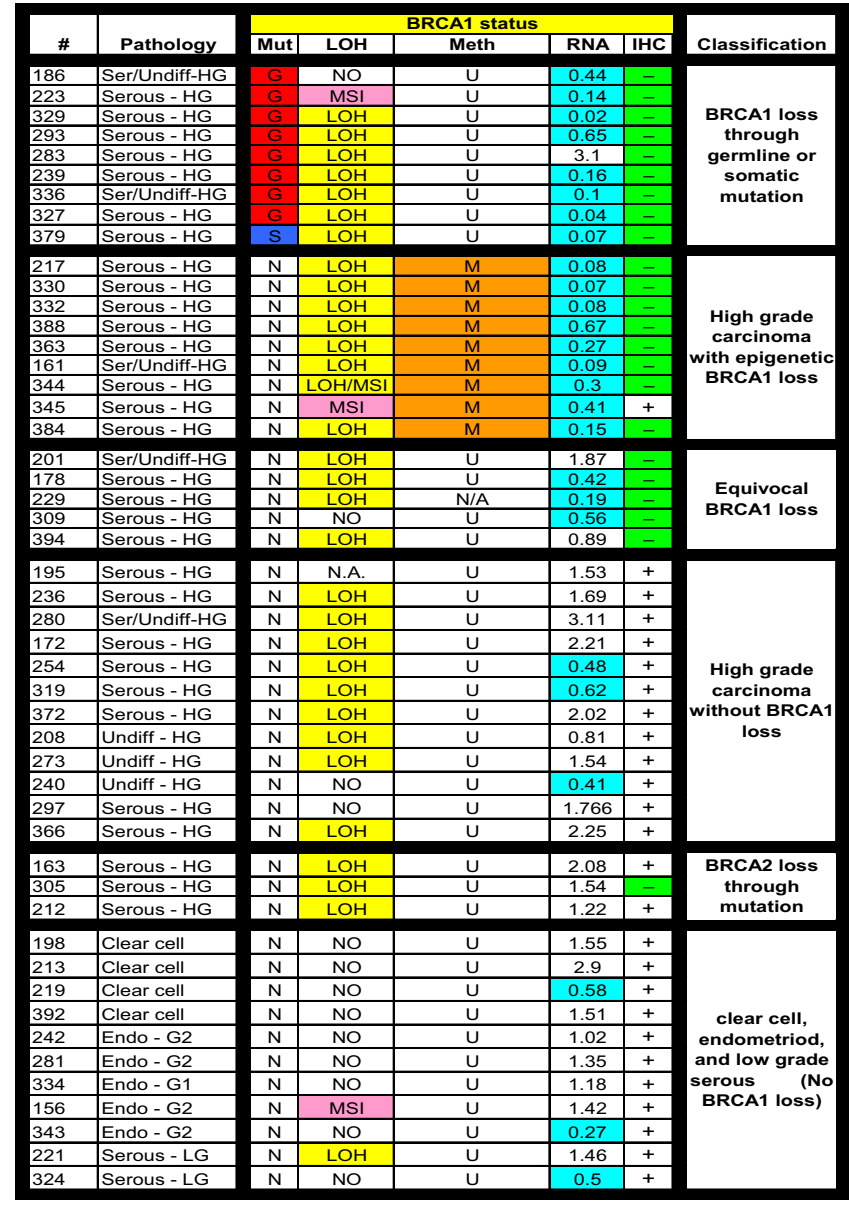

Figure 2

Summary of BRCAI abnormalities and associated features: Pathology refers to the tumor histopathology. Serous or Ser = serous carcinoma; Undiff = undifferentiated carcinoma; HG = high-grade; LG = low-grade; Clear cell = clear cell carcinoma; Endo = endometrioid carcinoma; $\mathrm{GI}=$ grade I; $\mathrm{G} 2=$ grade 2; $\mathrm{G} 3=$ grade 3. $\mathrm{BRCA} I$ Status: Mut = mutation; $\mathrm{G}=$ germline; $\mathrm{S}=$ somatic; $\mathrm{N}=$ no mutations. $\mathrm{LOH}=$ loss of heterozygosity where $\mathrm{LOH}$ indicates that loss of heterozygosity is present, NO indicates that loss of heterozygosity is not present, and MSI indicates that microsatellite instability is present in the tumor. Meth refers to BRCAI promoter hypermethylation. Tumors containing $\geq 4 \%$ fully methylated molecules are designated as methylated (M) and are highlighted in orange, whereas tumors containing $<4 \%$ are designated as unmethylated (U). RNA refers to relative RNA expression compared to the average RNA expression in all samples, where the average RNA expression $=1.0$. Tumors with relative RNA expression $<0.7$ are highlighted in aqua as showing BRCAI/ BRCA2 loss. IHC refers to BRCA1 immunohistochemistry; (+) indicates tumors with $>1 \%$ of nuclei stained positive for BRCAI, (-) indicates tumors with $<1 \%$ of nuclei positive. N/A indicates that the data is not available for technical reasons.

We further compared those tumors with either genetic or epigenetic loss of BRCA1 with high grade serous cancers without evidence of BRCA1 loss (Table 1). Representative immunohistochemical images for BRCA1, p53, and p21 from all three of these groups are shown in Figure 5. MIP copy number analysis of the nine tumours that had BRCA1 mutations showed that there was no loss or gain at the region of chromosome 3 that contains the gene for PIK3CA and only four (44\%) samples stained positively

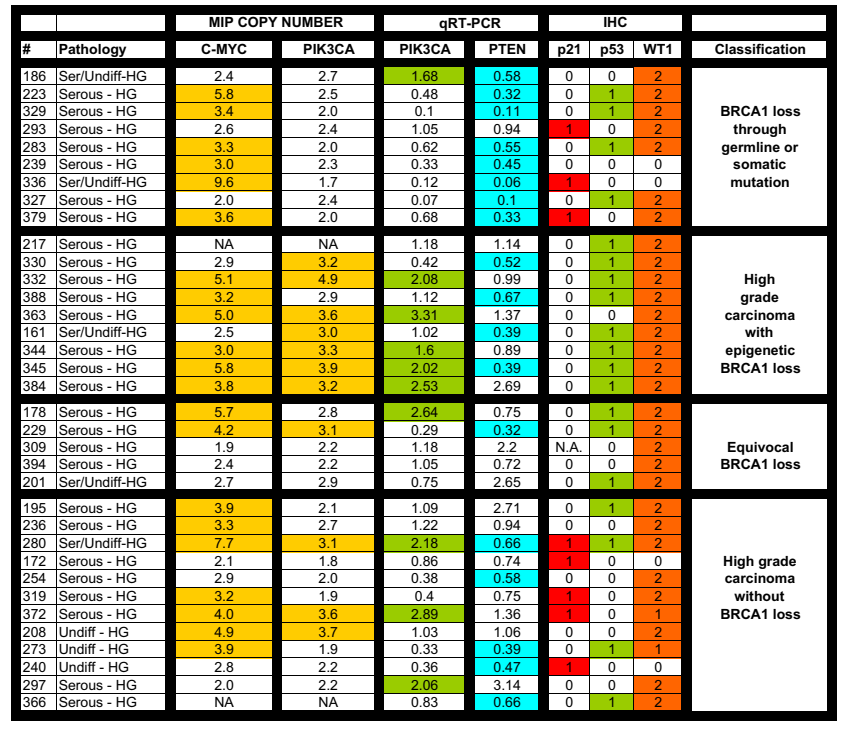

\section{Figure 3}

Summary of analysis of high grade (HG) serous/undifferentiated ovarian tumors: MIP copy number results are shown for c-myc and PIK3CA loci. MIP copy number values over 3.0 are highlighted and correspond to amplification. Relative mRNA levels for PIK3CA and PTEN were assessed using QRT-PCR; levels over I.3 (highlighted in green) are considered elevated and levels below 0.7 (highlighted in aqua) indicate decreased transcript levels. Associated immunohistochemical markers p2I, p53, and WT-I refer to immunohistochemical staining results. Scoring of immunostaining was done as follows: p2I: $0=<5 \%$ nuclei positive and I $=>5 \%$ of nuclei positive. p53: $0=<50 \%$ nuclei positive and I $=>50 \%$ of nuclei positive. WTI: $0=<5 \%$ nuclei positive, $I=5-50 \%$ nuclei positive, and $2=>50 \%$ nuclei positive. N/A indicates that the data is not available for technical reasons.

for p53. By contrast, of the samples that had loss of BRCA1 due to epigenetic events, seven of eight samples (88\%) had an increased PIK3CA copy number, and eight of nine samples ( $89 \%)$ stained positively for $\mathrm{p} 53$. In addition, high grade serous cancers without BRCA1 loss had low frequencies of positive p53 staining $(4 / 12,33 \%)$ and increased PIK3CA copy number $(3 / 12,25 \%)$, similar to cancers with BRCA1 mutations but distinct from cancers with epigenetic loss of BRCA1. In two cases (\#366 and \#217) we were unable to obtain MIP copy number data. It was noted that positive p53 staining was most often accompanied by negative $\mathrm{p} 21$ staining. The expression of p21 is increased in response to p53. High level overexpression of p53 correlates with p53 mutations and loss of function and would be anticipated to be associated with decreased p21 expression, as we observed. This p53+/p21immunophenotype was significantly more common in tumors with BRCA1 epigenetic loss than in tumors without BRCA1 loss (Table 1).

\section{Discussion}

The sub-classification of ovarian carcinomas, which is based on histopathological subtype and grade, is unable to adequately predict prognosis or response to treatment. Administration of adjuvant platinum/taxane chemother- 


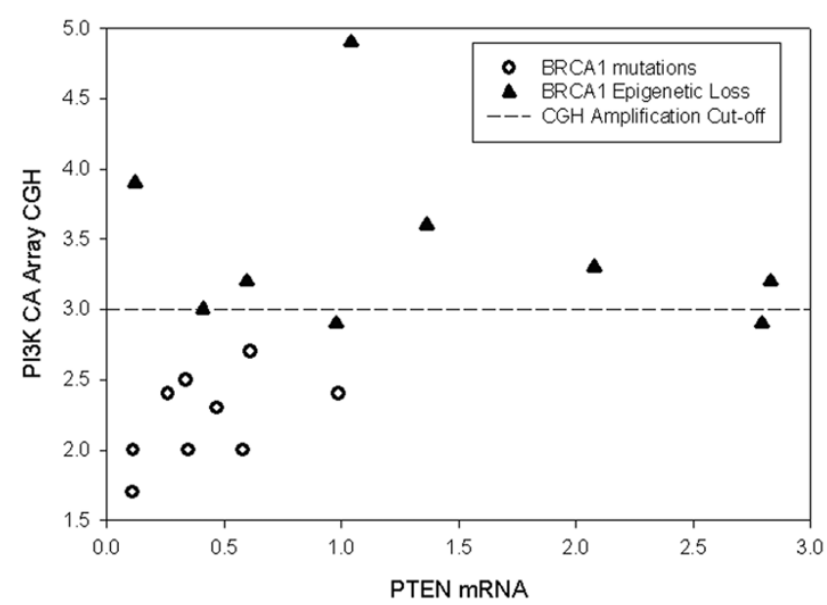

\section{Figure 4}

Correlation between decreased PTEN mRNA levels and amplification at the PIK3CA locus: Relative PTEN mRNA levels as determined by qRT$P C R$ are plotted along the $X$-axis and PIK3CA MIP copy number results are plotted along the $Y$-axis for high grade serous ovarian tumors with BRCAI mutations (open circles) and high grade serous ovarian tumors with epigenetic loss of BRCAI (filled triangles). MIP copy number values over 3.0 indicate amplification.

apy is the standard treatment for ovarian carcinoma following debulking surgery [58]. Approximately $70 \%$ of advanced-stage ovarian carcinomas, however, will recur with development, ultimately of platinum-resistant disease [59]. A comparison of clinical outcomes between ovarian cancer patients with BRCA1 promoter hypermethylation to patients with BRCA1 mutations and wild-type BRCA1 genes demonstrated that patients with BRCA1 promoter hypermethylation had significantly shorter survival times compared to the other two groups [60]. Ovarian carcinomas in patients with BRCA 1 , in contrast are associated with a favourable prognosis $[23,61]$. This data suggests that different abnormalities in BRCA1 could be associated with different clinical outcomes and possibly distinct alterations in other underlying molecular abnormalities. For example, the colon cancers from patients with inherited mutations in DNA mismatch repair genes differ from sporadic cancers with microsatellite instability due to hypermethylation of the MLH1 promoters [62], with respect to age of onset of disease, pathology, and molecular alterations [63].

We evaluated 49 ovarian carcinomas and categorized them according to pathology and BRCA1 and BRCA2 status. We further evaluated 35 high grade serous/undifferentiated tumours that we divided into four groups based on BRCA1 mutation status, expression, and promoter hypermethylation. We observed increased positive p53 immunohistochemical staining, which correlated with negative p21 immunostaining, in cancers with epigenetic
BRCA1 loss, compared to cancers with BRCA1 mutations and high grade serous/undifferentiated cancers without BRCA1 loss. p53 is a tumor suppressor that is involved in the progression of many cancers and is the most commonly mutated gene in ovarian carcinomas [37]. Typically, mutations in p53 result in accumulation of p53 in the nucleus and the majority of cases with abundant p53 detectable by immunohistochemistry are p53 mutant $[64,65]$. The p53 protein is an important mediator of apoptosis resulting from DNA damage, stress, or chemotherapy [66]. p21 is a downstream effector of the cell cycle arrest function of p53 and is upregulated at the transcriptional level by wildtype but not mutated p53 [67]. At present, p53 mutation status or expression is not used to guide clinical decisions [68]. We have observed that p53 overexpression correlates, as expected, with loss of p21 expression. Furthermore the phenotype of p53 overexpression with loss of p21 is significantly more common is high grade serous/undifferentiated tumors with epigenetic loss of BRCA1 compared to high grade serous/undifferentiated tumors without loss of BRCA1.

In addition, we found that ovarian carcinomas with loss of BRCA1 through genetic events and those with BRCA1 loss through epigenetic events both have activation of the PI3K/AKT pathway, though the mechanism of activation is different. PI3K phosphorylates phosphatidylinositol lipids in response to activation by receptor tyrosine kinases [69]. Its activity has been linked to proliferation, differentiation, cell adhesion, apoptosis, tumorigenesis, and angiogenesis [70]. PTEN is a phosphatase whose activity counters PI3K. The serine/threonine kinase AKT is a downstream target of PI3K [71] and the activity of one of its isoforms, AKT1, is elevated in ovarian carcinomas [72]. Both decreased PTEN levels and amplification of PIK3CA lead to increased phosphorylation of AKT and it has been previously shown that ovarian cancers often have alterations in PI3K and PTEN [73-75]. This is the first study, however, to report that decreased PTEN expression levels are associated with ovarian carcinomas carrying BRCA1 mutations while increased PI3KCA copy number is associated with ovarian carcinomas with epigenetic loss of BRCA1. It has been previously demonstrated in breast cancer and glioblastoma that PIK3CA mutations and PTEN loss are virtually mutually exclusive, suggesting that abrogation of just one of these proteins is sufficient for tumorigenesis $[76,77]$. We observe a similar result in our ovarian serous cancer samples; it is likely that deregulation of this pathway, while critical for tumorigenesis, can be accomplished through alteration of a single key molecule at which point selective pressure is relieved for altering other proteins involved in this signalling pathway. Our findings in serous ovarian carcinoma, and the previous results from studies of breast cancer and glioblastoma, are in contrast to ovarian carcinoma of 

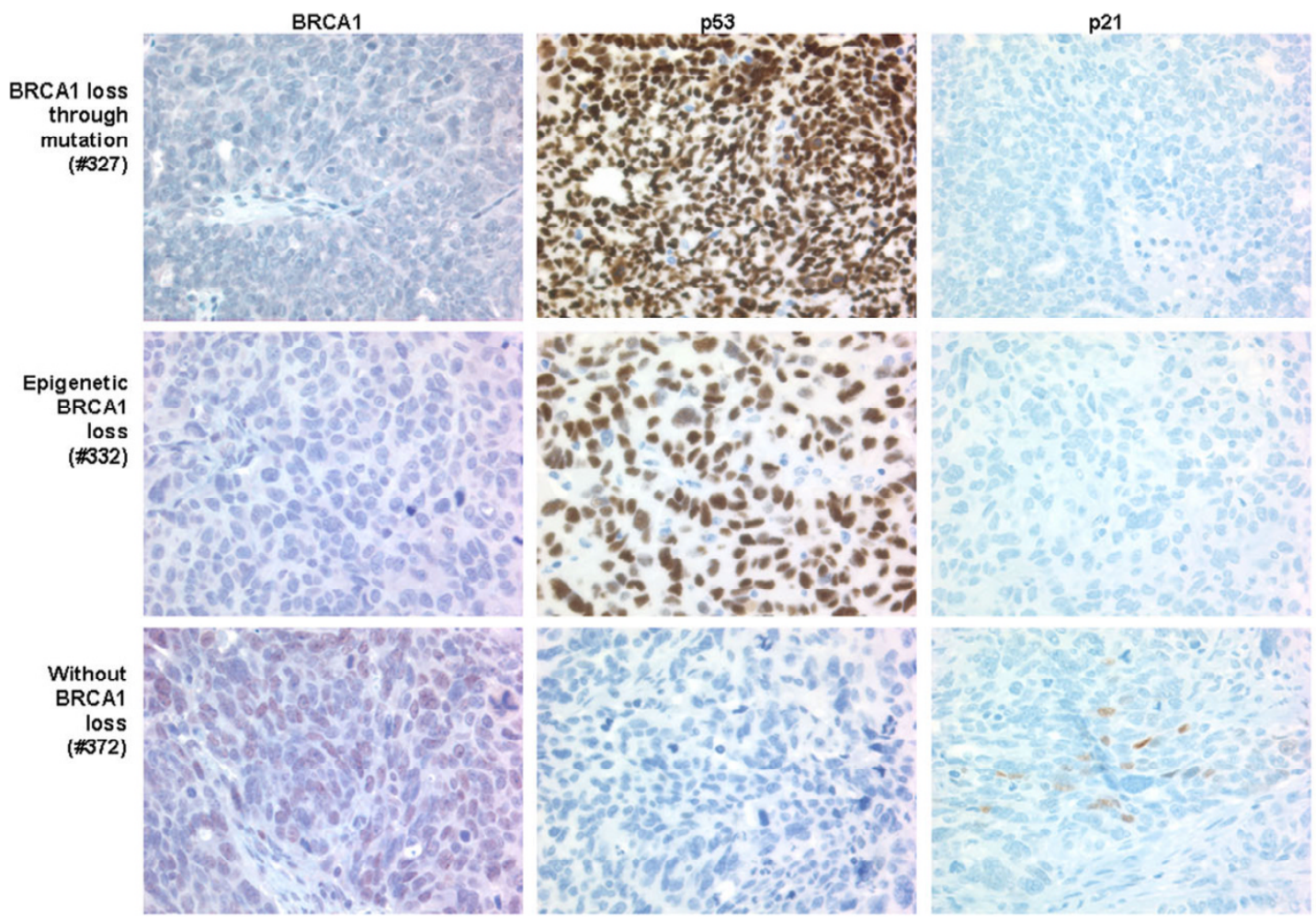

\section{Figure 5}

Immunohistochemistry results: Representative immunohistochemistry results for high grade serous ovarian tumors with BRCAI mutations (tumor \#327, top row), with epigenetic loss of BRCAI (tumor \#332, middle row), and without loss of BRCAI (tumor \#372, bottom row). Immunohistochemical staining is shown for BRCAI (left column), p53 (middle column) and p2I (right column).

endometrioid type [78], and endometrial cancer $[79,80]$, where PTEN mutations and PIK3CA mutations frequently co-exist. This is yet another example of molecular events during the genesis of ovarian cancer that show tumor cell type specificity, and reinforces the need to consider cell type differences in studies of ovarian cancer pathogenesis.

We would expect that cancers with activation of the PI3K/ AKT pathway may not respond well to common chemotherapy, as overexpression of activated AKT decreases apoptosis induced by paclitaxel in ovarian cancer cells [81] and introduction of the catalytic subunit of PI3K into ovarian cancer cells causes resistance to paclitaxel [82]. In addition, the PI3K inhibitor, LY294002, has been shown to decrease growth of ovarian carcinoma and ascites formation in mouse xenograft models of ovarian carcinoma [83]. As therapies continue to be developed that target the PI3K/AKT pathway, it will be essential to understand the molecular alterations that are affecting this pathway in different types of ovarian carcinomas.

The need for meaningful sub-classification of ovarian carcinoma is critical for improving the treatment and prognosis of patients. Though sub-classification may be done based on BRCA1 genetic testing, this cannot be done in a timely fashion such that it could be used to guide therapy

Table I: Comparison of PIK3 CA amplification or p53/p2I protein expression in High Grade Serous Ovarian Tumours

\begin{tabular}{|c|c|c|c|c|}
\hline \multirow[t]{2}{*}{ Group } & \multirow{2}{*}{ PIK3CA amplification (MIP copy number) } & \multicolumn{3}{|c|}{ p53/p2I IHC } \\
\hline & & $+/-$ & $+/+,-/-$ & $-/+$ \\
\hline BRCAI loss through mutation & $0 / 9^{*+}$ & $4 / 9$ & $2 / 9$ & $3 / 9$ \\
\hline BRCA I epigenetic loss & $7 / 8^{*+}$ & $8 / 9 * *$ & $1 / 9$ & $0 / 9$ \\
\hline No BRCAI loss & $3 / 11^{+}$ & $3 / 12^{* *}$ & $5 / 12$ & $4 / 12$ \\
\hline
\end{tabular}

$* p=0.02$ for pairwise comparison based on Bonferroni-Holmes corrected Fisher exact test

** $p=0.03$ for pairwise comparison based on Bonferroni-Holmes corrected Fisher exact test

$+p=0.001$ for threeway comparison based on Bonferroni-Holmes corrected Fisher exact test 
of patients newly diagnosed with ovarian cancer. This is extremely important as patients must embark on therapy shortly after diagnosis. In addition, as new therapeutics are developed, rapid identification of appropriate patients will be necessary for clinical trials. Our results demonstrate that it may be possible to categorize patients based on rapid molecular tests to identify patients who are likely to harbour BRCA1 mutations. Negative BRCA1 immunohistochemical staining, decreased BRCA1 mRNA, lack of PI3K amplification, and absence of BRCA1 promoter hypermethylation is an example of a molecular profile that could be used to identify these patients. This would also allow more cost effective and efficient mutation screening in patients presenting with ovarian carcinoma.

\section{Conclusion}

This is the first study to comprehensively examine data from detailed analysis of BRCA1 and BRCA2 abnormalities in ovarian cancer. Results presented here demonstrate that high grade serous/undifferentiated carcinomas can be subclassified based on the underlying BRCA abnormalities. Such clinically relevant subclassification is critical for developing specific treatements for ovarian cancer patients which will lead to improved prognosis and management of disease.

\section{Competing interests}

The author(s) declare that they have no competing interests.

\section{Authors' contributions}

JZP participated in the study design and coordination, patient recruitment, sample collection and handling, molecular analysis, immunohistochemical analysis, and drafting of the manuscript. AD participated in the tumor analysis, molecular analysis, and drafting of the manuscript. NB contributed to drafting of the manuscript. SY participated in the BRCA1/2 germline mutational analysis. AT participated in drafting of the manuscript. YR and $\mathrm{PK}$ are clinical genetic counsellors who were involved in recruitment of patients. SEK was involved in tissue banking and statistical analysis. KAB contributed to molecular analysis. MS contributed to design and validation of BRCA1 and BRCA2 primers for dHPLC mutation analysis. PTS and YK contributed to the MIP copy number assay experiments. DMM obtained consent for tissue banking and surgically collected tumor samples. DH was involved in BRCA1/2 germline mutation analysis and drafting of the manuscript. MF participated in the MIP copy number assay experiments. CBG was involved in study concept and design, pathological analysis, data analysis and interpretation, and drafting of the manuscript. JG participated in whole genome copy number analysis using MIP probes. DGH participated in study concept and design, data analysis and interpretation, and drafting of the man- uscript. All authors have read and approved the final version of the manuscript.

\section{Acknowledgements}

This work was funded by the National Cancer Institute of Canada (\# 01705I), the Michael Smith Foundation for Health Research Unit Grant (\#INRUA006045), and an NCl SPORE grant (\#P50 CA83639). This work was also supported by the U.S. Department of Energy, Office of Science, Office of Biological and Environmental Research (Contract DE-AC0376SF00098) and by the National Institutes of Health, National Cancer Institute P50 Grant CA 58207 and POI CA 64602 to JWG. NB and SEK are supported in part by OrCaRe. DGH and AD are supported by the Michael Smith Foundation for Health Research.

\section{References}

I. Milner BJ, Allan LA, Eccles DM, Kitchener HC, Leonard RC, Kelly KF, Parkin DE, Haites NE: p53 mutation is a common genetic event in ovarian carcinoma. Cancer Res 1993, 53:2128-2132.

2. Soslow RA, Shen PU, Chung MH, Isacson C: Distinctive p53 and mdm2 immunohistochemical expression profiles suggest different pathogenetic pathways in poorly differentiated endometrial carcinoma. Int J Gynecol Pathol 1998, 17:129-134.

3. Singer G, Oldt R 3rd, Cohen Y, Wang BG, Sidransky D, Kurman RJ, Shih le M: Mutations in BRAF and KRAS characterize the development of low-grade ovarian serous carcinoma. J Natl Cancer Inst 2003, 95:484-486.

4. Saegusa M, Hashimura M, Yoshida T, Okayasu I: beta-Catenin mutations and aberrant nuclear expression during endometrial tumorigenesis. Br J Cancer 200I, 84:209-2I7.

5. Enomoto T, Weghorst CM, Inoue M, Tanizawa O, Rice JM: K-ras activation occurs frequently in mucinous adenocarcinomas and rarely in other common epithelial tumors of the human ovary. Am J Pathol I99I, 139:777-785.

6. Bell DA: Origins and molecular pathology of ovarian cancer. Mod Pathol 2005, I 8(Suppl 2):S19-32.

7. Seidman JD, Kurman RJ: Pathology of ovarian carcinoma. Hematol Oncol Clin North Am 2003, I 7:909-925. vii

8. Seidman JD, Horkayne-Szakaly I, Haiba M, Boice CR, Kurman RJ, Ronnett $B M$ : The histologic type and stage distribution of ovarian carcinomas of surface epithelial origin. Int J Gynecol Pathol 2004, 23:41-44.

9. Gras E, Cortes J, Diez O, Alonso C, Matias-Guiu X, Baiget M, Prat J: Loss of heterozygosity on chromosome I 3q I 2-q I 4, BRCA-2 mutations and lack of BRCA-2 promoter hypermethylation in sporadic epithelial ovarian tumors. Cancer 200I, 92:787-795.

10. Koul A, Malander S, Loman N, Pejovic T, Heim S, Willen R, Johannsson $\mathrm{O}$, Olsson H, Ridderheim M, Borg AA: BRCAI and BRCA2 mutations in ovarian cancer: Covariation with specific cytogenetic features. Int J Gynecol Cancer 2000, I0:289-295.

II. Shaw PA, McLaughlin JR, Zweemer RP, Narod SA, Risch H, Verheijen RH, Ryan A, Menko FH, Kenemans P, Jacobs IJ: Histopathologic features of genetically determined ovarian cancer. Int J Gynecol Pathol 2002, $21: 407-41$ I.

12. Albertsen HM, Smith SA, Mazoyer S, Fujimoto E, Stevens J, Williams B, Rodriguez P, Cropp CS, Slijepcevic P, Carlson M, et al.: A physical map and candidate genes in the BRCAI region on chromosome I 7q I 2-2 I. Nat Genet 1994, 7:472-479.

13. Hall JM, Lee MK, Newman B, Morrow JE, Anderson LA, Huey B, King MC: Linkage of early-onset familial breast cancer to chromosome 17q21. Science 1990, 250:1684-1689.

14. Miki Y, Swensen J, Shattuck-Eidens D, Futreal PA, Harshman K, Tavtigian S, Liu Q, Cochran C, Bennett LM, Ding W, et al.: A strong candidate for the breast and ovarian cancer susceptibility gene BRCAI. Science 1994, 266:66-71.

15. Tavtigian SV, Simard J, Rommens J, Couch F, Shattuck-Eidens D, Neuhausen S, Merajver S, Thorlacius S, Offit K, Stoppa-Lyonnet D, et al:: The complete BRCA2 gene and mutations in chromosome I 3q-linked kindreds. Nat Genet 1996, I 2:333-337.

16. Wooster R, Neuhausen SL, Mangion J, Quirk Y, Ford D, Collins N, Nguyen K, Seal S, Tran T, Averill D, et al.: Localization of a breast cancer susceptibility gene, BRCA2, to chromosome 13q 12-13. Science 1994, 265:2088-2090. 
17. Jasin M: Homologous repair of DNA damage and tumorigenesis: the BRCA connection. Oncogene 2002, 21:8981-8993.

18. Venkitaraman AR: Cancer susceptibility and the functions of BRCAI and BRCA2. Cell 2002, 108:|7|-|82.

19. Boulton SJ: Cellular functions of the BRCA tumour-suppressor proteins. Biochem Soc Trans 2006, 34:633-645.

20. Pal T, Permuth-Wey J, Betts JA, Krischer JP, Fiorica J, Arango $H$ LaPolla J, Hoffman M, Martino MA, Wakeley K, et al.: BRCAI and BRCA2 mutations account for a large proportion of ovarian carcinoma cases. Cancer 2005, 104:2807-2816.

21. Risch HA, McLaughlin JR, Cole DE, Rosen B, Bradley L, Kwan E, Jack E, Vesprini DJ, Kuperstein G, Abrahamson JL, et al.: Prevalence and penetrance of germline BRCAI and BRCA2 mutations in a population series of 649 women with ovarian cancer. $A m J$ Hum Genet 200I, 68:700-710.

22. Merajver SD, Pham TM, Caduff RF, Chen M, Poy EL, Cooney KA, Weber BL, Collins FS, Johnston C, Frank TS: Somatic mutations in the BRCA I gene in sporadic ovarian tumours. Nat Genet 1995, 9:439-443

23. Cass I, Baldwin RL, Varkey T, Moslehi R, Narod SA, Karlan BY: Improved survival in women with BRCA-associated ovarian carcinoma. Cancer 2003, 97:2187-2195.

24. Esteller M, Silva JM, Dominguez G, Bonilla F, Matias-Guiu X, Lerma E, Bussaglia E, Prat J, Harkes IC, Repasky EA, et al.: Promoter hypermethylation and BRCAI inactivation in sporadic breast and ovarian tumors. I Natl Cancer Inst 2000, 92:564-569.

25. Futreal PA, Liu Q, Shattuck-Eidens D, Cochran C, Harshman K, Tavtigian S, Bennett LM, Haugen-Strano A, Swensen J, Miki Y, et al. BRCAI mutations in primary breast and ovarian carcinomas. Science 1994, 266: 120-122.

26. Thrall M, Gallion HH, Kryscio R, Kapali M, Armstrong DK, DeLoia JA BRCAI expression in a large series of sporadic ovarian carcinomas: a Gynecologic Oncology Group study. Int J Gynecol Cancer 2006, I6(Suppl I):|66-I7|

27. Wiley A, Katsaros D, Chen H, Rigault de la Longrais IA, Beeghly A, Puopolo M, Singal R, Zhang Y, Amoako A, Zelterman D, et al.: Aberrant promoter methylation of multiple genes in malignant ovarian tumors and in ovarian tumors with low malignant potential. Cancer 2006, 107:299-308.

28. Armes JE, Venter DJ: The pathology of inherited breast cancer. Pathology 2002, 34:309-3।4.

29. Goffin JR, Chappuis PO, Begin LR, Wong N, Brunet JS, Hamel N, Paradis AJ, Boyd J, Foulkes WD: Impact of germline BRCAI mutations and overexpression of $\mathrm{p} 53$ on prognosis and response to treatment following breast carcinoma: I0-year follow up data. Cancer 2003, 97:527-536.

30. Lakhani SR, Van De Vijver MJ, Jacquemier J, Anderson TJ, Osin PP McGuffog L, Easton DF: The pathology of familial breast cancer: predictive value of immunohistochemical markers estrogen receptor, progesterone receptor, HER-2, and $\mathrm{p} 53$ in patients with mutations in BRCAI and BRCA2. J Clin Oncol 2002, 20:2310-2318

31. Boyd J, Sonoda Y, Federici MG, Bogomolniy F, Rhei E, Maresco DL, Saigo PE, Almadrones LA, Barakat RR, Brown CL, et al:: Clinicopathologic features of BRCA-linked and sporadic ovarian cancer. Jama 2000, 283:2260-2265.

32. Werness BA, Ramus SJ, DiCioccio RA, Whittemore AS, Garlinghouse-Jones K, Oakley-Girvan I, Tsukada Y, Harrington P, Gayther SA, Ponder BA, et al.: Histopathology, FIGO stage, and BRCA mutation status of ovarian cancers from the Gilda Radner Familial Ovarian Cancer Registry. Int J Gynecol Pathol 2004, 23:29-34.

33. Jazaeri AA, Yee CJ, Sotiriou C, Brantley KR, Boyd J, Liu ET: Gene expression profiles of BRCAI-linked, BRCA2-linked, and sporadic ovarian cancers. J Natl Cancer Inst 2002, 94:990-1000.

34. Bryant HE, Schultz N, Thomas HD, Parker KM, Flower D, Lopez E, Kyle S, Meuth M, Curtin NJ, Helleday T: Specific killing of BRCA2deficient tumours with inhibitors of poly(ADP-ribose) polymerase. Nature 2005, 434:913-917.

35. Farmer H, McCabe N, Lord CJ, Tutt AN, Johnson DA, Richardson TB, Santarosa M, Dillon KJ, Hickson I, Knights C, et al.: Targeting the DNA repair defect in BRCA mutant cells as a therapeutic strategy. Nature 2005, 434:917-921.

36. Turner N, Tutt $A$, Ashworth $A$ : Hallmarks of 'BRCAness' in sporadic cancers. Nat Rev Cancer 2004, 4:8।4-8।9.
37. Chan KY, Ozcelik H, Cheung AN, Ngan HY, Khoo US: Epigenetic factors controlling the BRCAI and BRCA2 genes in sporadic ovarian cancer. Cancer Res 2002, 62:4I II-4I56.

38. Collins N, Wooster R, Stratton MR: Absence of methylation of CpG dinucleotides within the promoter of the breast cancer susceptibility gene BRCA2 in normal tissues and in breast and ovarian cancers. Br / Cancer 1997, 76: II50-6.

39. Gras E, Cortes J, Diez O, Alonso C, Matias-Guiu X, Baiget M, Prat J: Loss of heterozygosity on chromosome I3q / 2-q 14, BRCA-2 mutations and lack of BRCA-2 promoter hypermethylation in sporadic epithelial ovarian tumors. Cancer 200I, 92:787-95.

40. Aunoble B, Sanches R, Didier E, Bignon YJ: Major oncogenes and tumor suppressor genes involved in epithelial ovarian cancer (review). Int J Oncol 2000, 16:567-576.

4I. Bellacosa A de Feo D, Godwin AK, Bell DW, Cheng JQ, Altomare DA, Wan M, Dubeau L, Scambia G, Masciullo V, et al.: Molecular alterations of the AKT2 oncogene in ovarian and breast carcinomas. Int / Cancer 1995, 64:280-285.

42. Cheng JQ, Godwin AK, Bellacosa A, Taguchi T, Franke TF, Hamilton TC, Tsichlis PN, Testa JR: AKT2, a putative oncogene encoding a member of a subfamily of protein-serine/threonine kinases, is amplified in human ovarian carcinomas. Proc Natl Acad Sci USA 1992, 89:9267-927I.

43. Yuan ZQ, Feldman RI, Sun M, Olashaw NE, Coppola D, Sussman GE, Shelley SA, Nicosia SV, Cheng JQ: Inhibition of JNK by cellular stress- and tumor necrosis factor alpha-induced AKT2 through activation of the NF kappa B pathway in human epithelial. Cells J Biol Chem 2002, 277:29973-29982.

44. Malpica A, Deavers MT, Lu K, Bodurka DC, Atkinson EN, Gershenson DM, Silva EG: Grading ovarian serous carcinoma using a two-tier system. Am J Surg Pathol 2004, 28:496-504.

45. Silverberg SG: Histopathologic grading of ovarian carcinoma: a review and proposal. Int J Gynecol Pathol 2000, 19:7-15.

46. Wang C, Horiuchi A, Imai T, Ohira S, Itoh K, Nikaido T, Katsuyama $Y$, Konishi I: Expression of BRCAI protein in benign, borderline, and malignant epithelial ovarian neoplasms and its relationship to methylation and allelic loss of the BRCAI gene. Pathol 2004, 202:2 I 5-223.

47. Regitnig P, Moser R, Thalhammer M, Luschin-Ebengreuth G, Ploner F, Papadi H, Tsybrovskyy O, Lax SF: Microsatellite analysis of breast carcinoma and corresponding local recurrences. J Pathol 2002, 198:190-197.

48. Liu W, Smith DI, Rechtzigel KJ, Thibodeau SN, James CD: Denaturing high performance liquid chromatography (DHPLC) used in the detection of germline and somatic mutations. Nucleic Acids Res 1998, 26: 1396-I 400.

49. Hogervorst FB, Nederlof PM, Gille J], McElgunn C], Grippeling M, Pruntel R, Regnerus R, van Welsem T, van Spaendonk R, Menko FH, et al:: Large genomic deletions and duplications in the BRCAI gene identified by a novel quantitative method. Cancer Res 2003, 63:1449-1453.

50. Eads CA, Lord RV, Kurumboor SK, Wickramasinghe K, Skinner ML, Long TI, Peters JH, DeMeester TR, Danenberg KD, Danenberg PV, et al.: Fields of aberrant CpG island hypermethylation in Barrett's esophagus and associated adenocarcinoma. Cancer Res 2000, 60:502I-5026.

51. Eads CA, Lord RV, Wickramasinghe K, Long TI, Kurumboor SK, Bernstein L, Peters JH, DeMeester SR, DeMeester TR, Skinner KA, et al.: Epigenetic patterns in the progression of esophageal adenocarcinoma. Cancer Res 2001, 61:3410-3418.

52. Taniguchi T, Tischkowitz M, Ameziane N, Hodgson SV, Mathew CG Joenje H, Mok SC, D'Andrea AD: Disruption of the Fanconi anemia-BRCA pathway in cisplatin-sensitive ovarian tumors. Nat Med 2003, 9:568-574.

53. Hardenbol P, Yu F, Belmont J, Mackenzie J, Bruckner C, Brundage T, Boudreau A, Chow S, Eberle J, Erbilgin A, et al.: Highly multiplexed molecular inversion probe genotyping: over 10,000 targeted SNPs genotyped in a single tube assay. Genome Res 2005, I5:269-275.

[http://www.affymetrix.com/products/application/ targeted genotyping.aff $x$ ]

5. Wang Y, Moorhead M, Karlin-Neumann G, Falkowski M, Chen C, Siddiqui F, Davis RW, Willis TD, Faham M: Allele quantification using molecular inversion probes (MIP). Nucleic Acids Res 2005, 33:el83. 
56. Burden CJ, Pittelkow YE, Wilson SR: Statistical analysis of adsorption models for oligonucleotide microarrays. Stat Appl Genet Mol Biol 2004, 3:. Article35

57. Al-Hussaini M, Stockman A, Foster H, McCluggage WG: WT-I assists in distinguishing between ovarian from uterine serous carcinoma and in distinguishing between serous and endometrioid ovarian carcinoma. Histopathology 2004, 44:109-II5

58. Bristow RE, Tomacruz RS, Armstrong DK, Trimble EL, Montz FJ: Survival effect of maximal cytoreductive surgery for advanced ovarian carcinoma during the platinum era: a meta-analysis. J Clin Oncol 2002, 20: I248-I 259.

59. Markman M, Liu PY, Wilczynski S, Monk B, Copeland LJ, Alvarez RD, Jiang C, Alberts D: Phase III randomized trial of 12 versus 3 months of maintenance paclitaxel in patients with advanced ovarian cancer after complete response to platinum and paclitaxel-based chemotherapy: a Southwest Oncology Group and Gynecologic Oncology Group trial. I Clin Oncol 2003, $21: 2460-2465$

60. Chiang JW, Karlan BY, Cass L, Baldwin RL: BRCAl promoter methylation predicts adverse ovarian cancer prognosis. Gynecol Oncol 2006, I 0 I:403-4I 0.

61. Majdak EJ, Debniak J, Milczek T, Cornelisse C], Devilee P, Emerich J, Jassem J, De Bock GH: Prognostic impact of BRCAI pathogenic and BRCAI/BRCA2 unclassified variant mutations in patients with ovarian carcinoma. Cancer 2005, I 04: I004-I0I 2.

62. McGivern A, Wynter CV, Whitehall VL, Kambara T, Spring KJ, Walsh MD, Barker MA, Arnold S, Simms LA, Leggett BA, et al.: Promoter hypermethylation frequency and BRAF mutations distinguish hereditary non-polyposis colon cancer from sporadic MSI-H colon cancer. Fam Cancer 2004, 3: I 0I-107.

63. Jass JR, Walsh MD, Barker M, Simms LA, Young J, Leggett BA: Distinction between familial and sporadic forms of colorectal cancer showing DNA microsatellite instability. Eur J Cancer 2002, 38:858-866

64. Sasano H, Goukon Y, Nishihira T, Nagura H: In situ hybridization and immunohistochemistry of p53 tumor suppressor gene in human esophageal carcinoma. Am J Pathol I992, I 4 I:545-550.

65. Esrig D, Spruck CH 3rd, Nichols PW, Chaiwun B, Steven K, Groshen S, Chen SC, Skinner DG, Jones PA, Cote RJ: p53 nuclear protein accumulation correlates with mutations in the p53 gene, tumor grade, and stage in bladder cancer. Am J Pathol 1993 143: 1389-1397.

66. Roos WP, Kaina B: DNA damage-induced cell death by apoptosis. Trends Mol Med 2006, I 2:440-450.

67. el-Deiry WS, Tokino T, Velculescu VE, Levy DB, Parsons R, Trent JM, Lin D, Mercer WE, Kinzler KW, Vogelstein B: WAF I, a potential mediator of p53 tumor suppression. Cell 1993, 75:817-825.

68. Agarwal R, Kaye SB: Expression profiling and individualisation of treatment for ovarian cancer. Curr Opin Pharmacol 2006. 6:345-349.

69. Chen HC, Guan JL: Association of focal adhesion kinase with its potential substrate phosphatidylinositol 3-kinase. Proc Natl Acad Sci USA 1994, 91:10148-10152.

70. Roymans D, Slegers H: Phosphatidylinositol 3-kinases in tumor progression. Eur J Biochem 200I, 268:487-498.

7I. Jiang BH, Aoki M, Zheng JZ, Li J, Vogt PK: Myogenic signaling of phosphatidylinositol 3-kinase requires the serine-threonine kinase Akt/protein kinase B. Proc Natl Acad Sci USA 1999, 96:2077-208I

72. Sun M, Wang G, Paciga JE, Feldman RI, Yuan ZQ, Ma XL, Shelley SA, Jove R, Tsichlis PN, Nicosia SV, et al.: AKTI/PKBalpha kinase is frequently elevated in human cancers and its constitutive activation is required for oncogenic transformation in NIH3T3 cells. Am J Pathol 200I, I 59:431-437.

73. Schondorf T, Gohring UJ, Roth G, Middel I, Becker M, Moser N, Valter MM, Hoopmann $M$ : Time to progression is dependent on the expression of the tumour suppressor PTEN in ovarian cancer patients. Eur J Clin Invest 2003, 33:256-260

74. Shayesteh L, Lu Y, Kuo WL, Baldocchi R, Godfrey T, Collins C, Pinke $D$, Powell B, Mills GB, Gray JW: PIK3CA is implicated as an oncogene in ovarian cancer. Nat Genet 1999, 21:99-102.

75. Yokomizo A, Tindall DJ, Hartmann L, Jenkins RB, Smith DI, Liu W Mutation analysis of the putative tumor suppressor PTEN/ MMACI in human ovarian cancer. Int J Oncol 1998, I 3: 101-105.
76. Saal LH, Holm K, Maurer M, Memeo L, Su T, Wang X, Yu JS, Malmstrom PO, Mansukhani M, Enoksson J, et al.: PIK3CA mutations correlate with hormone receptors, node metastasis, and ERBB2, and are mutually exclusive with PTEN loss in human breast carcinoma. Cancer Res 2005, 65:2554-2559.

77. Broderick DK, Di C, Parrett TJ, et al.: Mutations of PIK3CA in anaplastic oligodendrogliomas, high-grade astrocytomas, and medulloblastomas. Cancer Res 2004, 64:5048-5050.

78. Wu r, Hendrix-Lucas N, Kuick R, Zhai Y, Schwartz DR, Akyol A Hanash S, Misek DE, Katabuchi H, Williams BO, Fearon E, Cho KR: Mouse model of human ovarian endometrioid adenocarcinoma based on somatic defects in the Wnt-catenin and PICK/Pten signaling pathways. Cancer Cell 2007, I I:32 I-333.

79. Oda K, Stokoe D, Taketani Y, McCormick F: High frequency of coexistent mutations of PIK3CA and PTEN genes in endometrial carcinoma. Cancer Res 2005, 65:10669-10673.

80. Hayes MP, Wang H, Espinal-Witter R, Douglas W, Solomon G, Baker S], Ellenson LH: PIK3CA and PTEN mutations in endometrioid carcinoma and complex atypical hyperplasia. Clin Cancer Res 2006, I 2:5932-5935.

81. Page C, Lin HJ, Jin Y, Castle VP, Nunez G, Huang M, Lin J: Overexpression of Akt/AKT can modulate chemotherapy-induced apoptosis. Anticancer Res 2000, 20:407-416.

82. Hu L, Hofmann J, Lu Y, Mills GB, Jaffe RB: Inhibition of phosphatidylinositol 3'-kinase increases efficacy of paclitaxel in in vitro and in vivo ovarian cancer models. Cancer Res 2002 , 62:1087-1092.

83. Hu L, Zaloudek C, Mills GB, Gray J, Jaffe RB: In vivo and in vitro ovarian carcinoma growth inhibition by a phosphatidylinositol 3-kinase inhibitor (LY294002). Clin Cancer Res 2000, 6:880-886.

\section{Pre-publication history}

The pre-publication history for this paper can be accessed here:

http://www.biomedcentral.com/1471-2407/8/17/prepub
Publish with Bio Med Central and every scientist can read your work free of charge

"BioMed Central will be the most significant development for disseminating the results of biomedical research in our lifetime. "

Sir Paul Nurse, Cancer Research UK

Your research papers will be:

- available free of charge to the entire biomedical community

- peer reviewed and published immediately upon acceptance

- cited in PubMed and archived on PubMed Central

- yours - you keep the copyright
BiolMedcentral 